\title{
Radiographic Evaluation of the Appearance and Closure Time of Growth Plates of Radius and Ulna Bones in Nigerian Indigenous Dogs
}

\author{
Oviawe $\mathrm{EI}^{1^{*}}$, Yakubu AS ${ }^{1}$, Kene $\mathrm{ROC}^{1}$ and Shehu $\mathrm{SA}^{2}$ \\ ${ }^{1}$ Departement of Veterinary Surgery and Radiology, Usmanu Danfodiyo University Sokoto, Nigeria \\ ${ }^{2}$ Department of Veterinary Anatomy, Usmanu Danfodiyo University Sokoto, Nigeria
}

*Corresponding author: Oviawe EI, Departement of Veterinary Surgery and Radiology, Usmanu Danfodiyo University Sokoto, Nigeria, Tel: +2348062449793, E-mail: kaeteimnoh@gmail.com

Citation: Oviawe EI, Yakubu AS, Kene ROC, Shehu SA (2018) Radiographic Evaluation of the Appearance and Closure Time of Growth Plates of Radius and Ulna Bones in Nigerian Indigenous Dogs. J Vet Ani Res 1: 101

Article history: Received: 09 April 2018, Accepted: 18 May 2018, Published: 21 May 2018

\begin{abstract}
Growth plates are specialized cartilages extending longitudinally between the epiphysis and metaphysis of immature long bones. The aim of this study was to evaluate the appearance, sequential thickness and closure time of the proximal and distal growth plates of radius and ulna bones in Nigerian indigenous dogs considering the paucity of information on these areas. In this study, a total of sixteen ( 8 male and 8 females) apparently healthy Nigerian indigenous dogs were used over a period of 48 weeks. Medio-lateral radiographic exposures of the right forelimb of each puppy were taken at weekly intervals up to a period of 9 weeks and thereafter at 4 weeks interval. The radiographic images were reviewed and interpreted. The results obtained showed that the growth plate of the distal epiphysis of the radius was the first to appear at week 2 in some dogs and at 3 weeks in others, while that of the proximal epiphysis of the radius appeared second at 5 weeks in all the dogs. The growth plate of the distal epiphysis of the ulna bone appeared at 6 weeks while that of the proximal epiphysis of the ulna appeared at 8 weeks in all the dogs. The proximal ulna growth plate was the first to fuse at 24 weeks followed by the proximal radius at 28 weeks, then the distal ulna at 32 weeks while the distal radius was the last to fuse at 36 weeks in most of the dogs.
\end{abstract}

Keywords: Bones; Growth Plates; Nigerian Dogs; Radius; Ulna; Radiography

\section{Introduction}

Monitoring the radius and ulna bones is necessary in veterinary radiology as it provides a guide to surgeons on the choice of surgical procedures to be performed in the growth plate region considering the time at which the growth plate of these bones appears, reach their proper anatomical shape and finally fuse.

Growth plates are also known asphyses, epiphyseal plate, metaphyseal growth plate, epiphyseal cartilage and epiphyseal disk [1]. They are the endochondral ossification areas of long bones [2] which are specialized cartilages extending longitudinally between the epiphysis and metaphysis of immature long bones. The growth plate appears radiolucent on radiographs [3] which closes as the animal matures and at this age of maturity, the epiphysis fuses with the metaphysis to become a single bone [4].

The age at growth plate closure is expected to depend on breed genetic factors, physiological conditions, disease, cross-breeding, nutritional conditions, and the management system [5].

For evaluation of growth plates, radiographic imaging is an effective method to demonstrate the time of appearance and closure of growth plates which are very important in order to decide whether there is normal or abnormal development of the bone and also to know the age at which interruption of the growth plate region using threaded devices can be performed without interrupting the growth plate. In support of this, several reports have been documented on the growth plate of other species and breeds of dogs: cat's [12] mice [7] cattle [13], monkey [14], sheep [15], goat [16], in horse [17,18]. However, there was limited study on the radiographic observations of the forelimb of Nigerian indigenous dogs. Therefore, the objective of this study was to observe the time of appearance, sequential thickness and closure of growth plates of radius and ulna bones of male and female Nigerian indigenous dogs by using radiograph.

\section{Material and Methods}

Sixteen ( 8 males, 8 females) apparently healthy Nigerian indigenous puppies, weighing an average of $0.3 \mathrm{~kg}$ at the beginning of the study (week 1), were obtained from three different liters. They were physically examined to ascertain their health status. Each 
puppy was dewormed and vaccinated against rabies, parvovirus enteritis, para-influenza, hepatitis and canine distemper and were maintained on daily portion of jollof rice, gari with soup, beans and clean drinking water was provided ad libitum.

At week 1, animals were placed on the right lateral recumbency on the x-ray table for radiography without sedation till they were 4 weeks, when the puppies were sedated in order to immobilize them during radiography. Xylazine hydrochloride (0.2mg/ $\mathrm{kg}$ ) (VMD Arendonk, Belgium ${ }^{\oplus}$ ) and Atropine $\left(0.04 \mathrm{mg} / \mathrm{kg}\right.$ ) (8-Methyl-8-azabicyclo 3.2.1, Atropen ${ }^{\circledR}$ ) combination administered intramuscularly [19] were used to achieve sedation. The weight of each dog was taken before each radiograph and radiographic exposures were scheduled at weekly interval till 9 weeks and thereafter at every four weeks interval till 48 weeks using a method adopted by [11]. Puppies were radiographed using Power mobile x-ray machine (LX-8 MOB) installed at Veterinary radiology unit of Usmanu Danfodiyo University Sokoto. Accurate settings of between 50-60kV, 8-12mAs [20] were used for this study. Mediolateral radiographs were taken with the animal on right lateral recumbency [21]. The right limb was placed on the loaded cassette containing the x-ray film on the x-ray table and the light beam was collimated with the primary beam focused on the diaphysis of the radius and ulna bone. The left limb was retracted caudally using gauze bandage with the head and neck slightly extended out of the primary beam. After taking a radiograph in the x-ray room, the cassette was taken to the dark room for identification and manual processing of the films in the processing tank after which it was allowed to dry. The thickness of the growth plate was measured using an electronic digital caliper (Raider ${ }^{\circledast}$ ) (Figures 1,2,3,4 and 5) in mm until the growth plate started fusing (partial union). The x-ray films were viewed by placed them on an X-ray film illuminator (Techmel and Techmel Texas U.S.A). This study was conducted by a team of professionals comprising of an anatomist, a radiologist, and surgeons who organized the work, reviewed and interpreted the radiographs. Nigerian Indigenous dogs are small breed dogs. The weight of the dogs at the end of the study had an average of $14.6 \mathrm{~kg}$

\section{Images showing the development and partial ossification of growth plates of the radius and ulna bones}

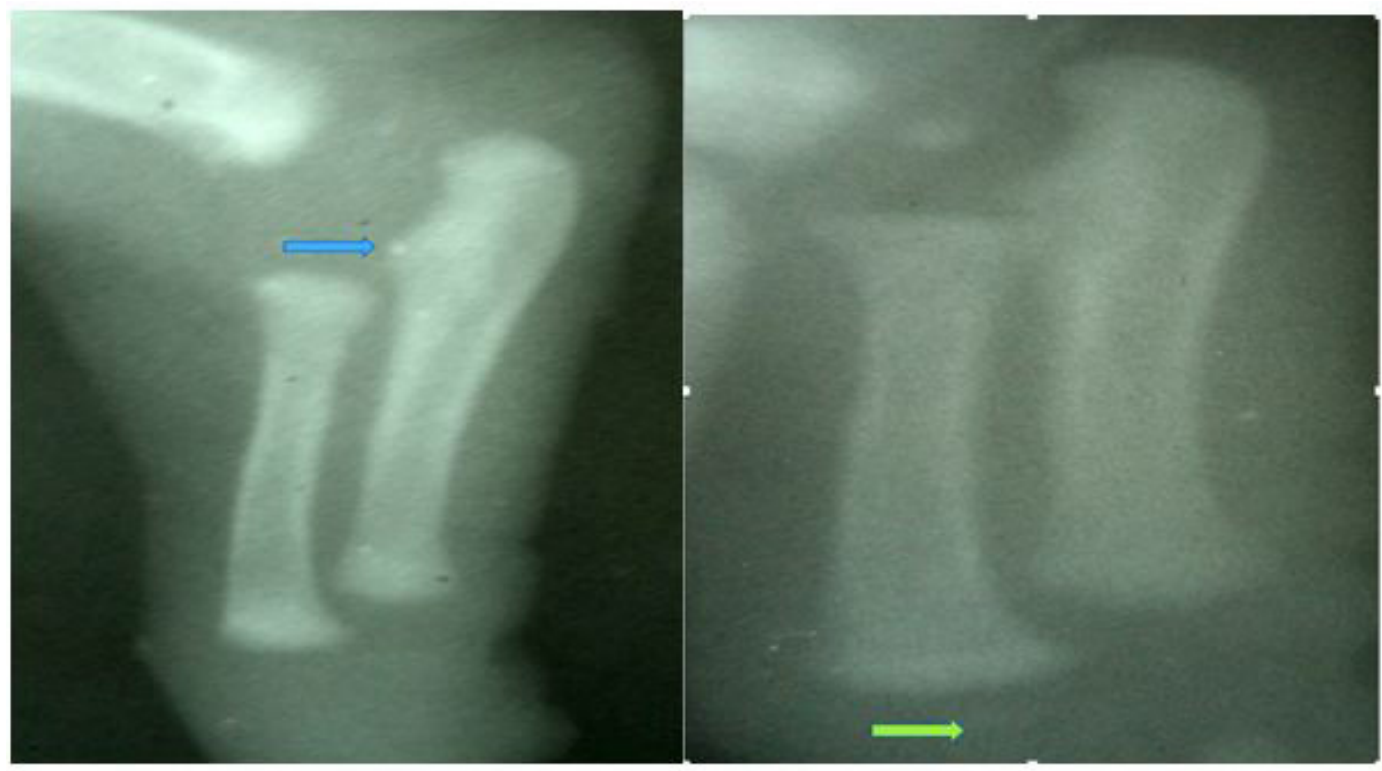

Figure 1: (week 1)

Figure 2: (2 weeks)
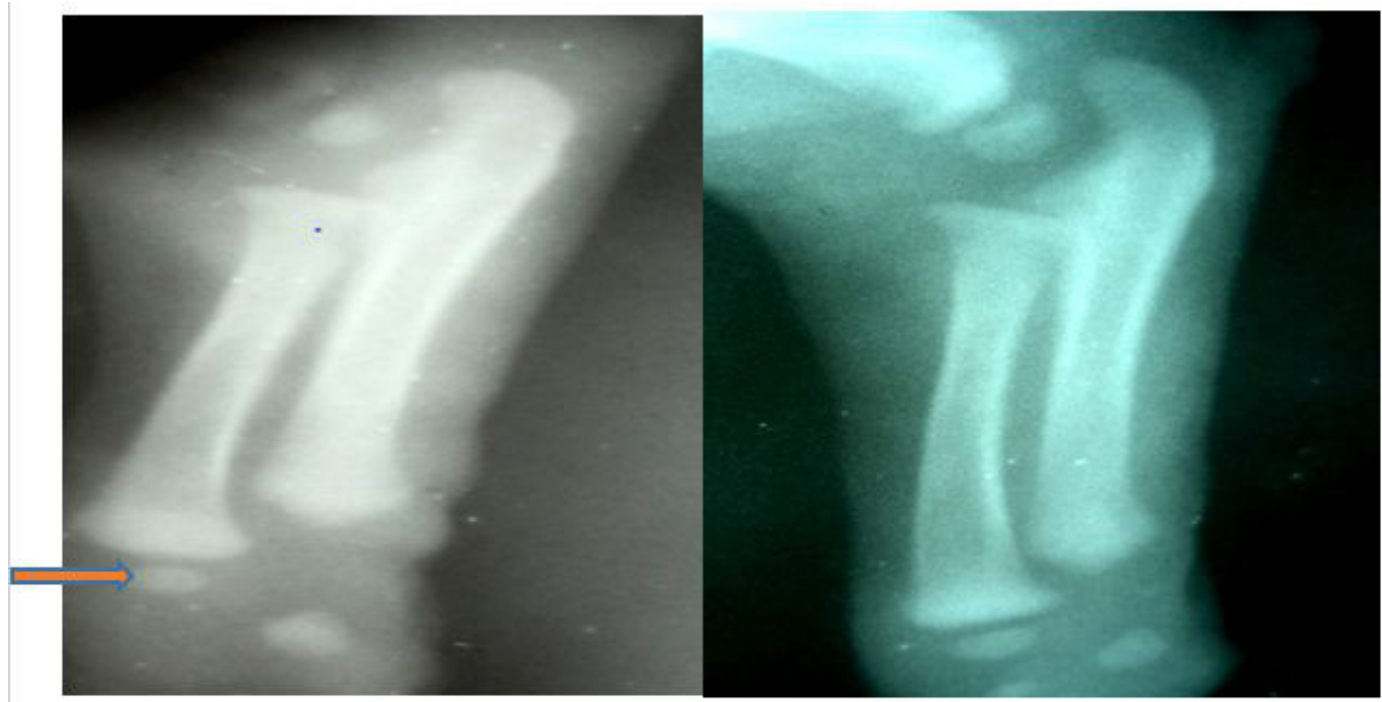

Figure 3: (3 weeks)

Figure 4: (4 weeks) 


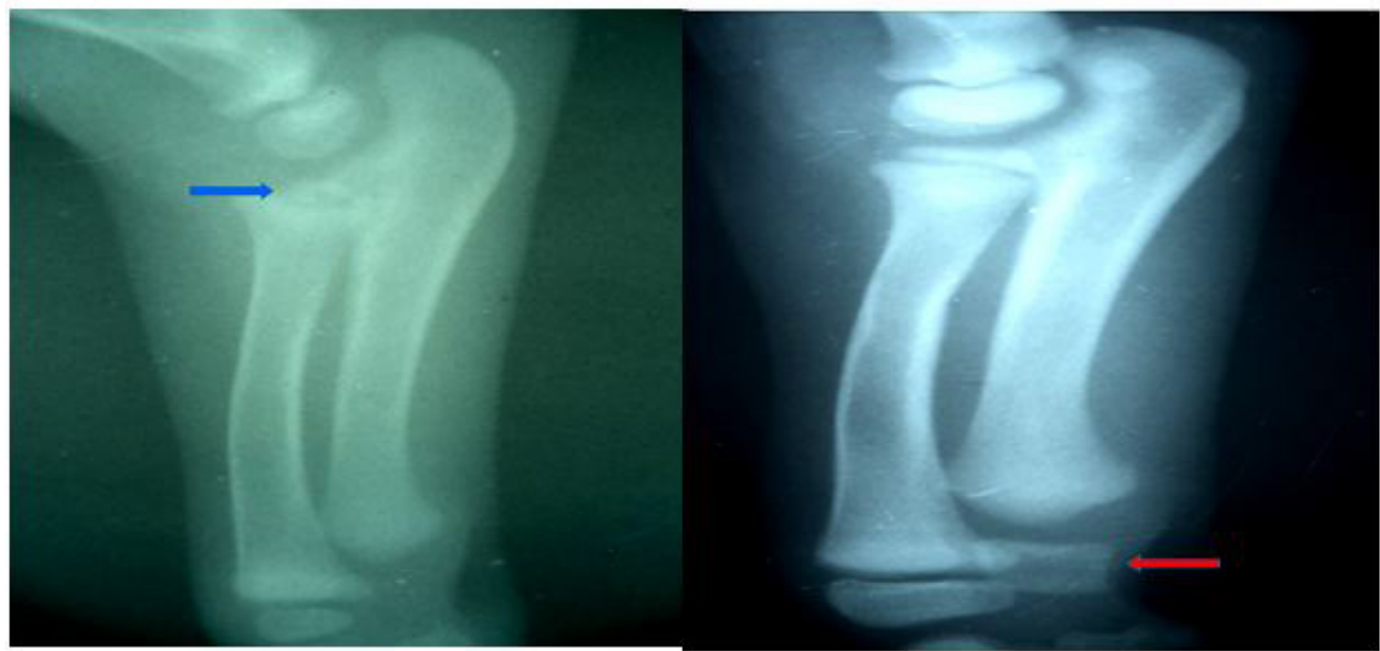

Figure 5: (5 weeks)

Figure 6: (6 weeks)

\section{Results}

The radiolucent space located between the epiphysis and the metaphysis is the growth plate which appeared after the appearance of secondary ossification centers of each bone. The first growth plate to appear was the distal radius at 2 weeks (Figure 2) as a small ovoid structure which was present in 12 dogs ( 6 males and 6 females) but absent in 4 dogs which appeared at 3 weeks in others, followed by the proximal radius which appeared at 5 weeks (Figure 5) in all the dogs, then the distal ulna that appeared at 6 weeks (Figure 6) in all the dogs and finally the proximal ulna that all appeared at 8 weeks (Figure 8 ) for all the dogs.

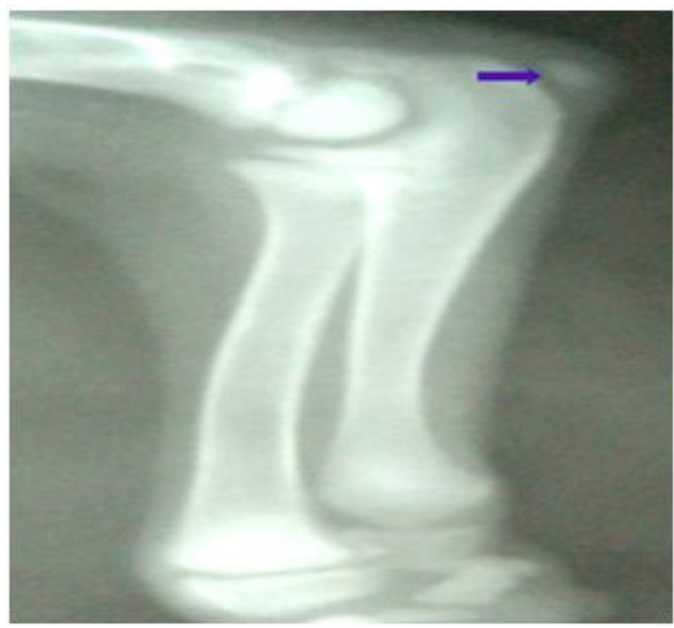

Figure 7: (8 weeks)

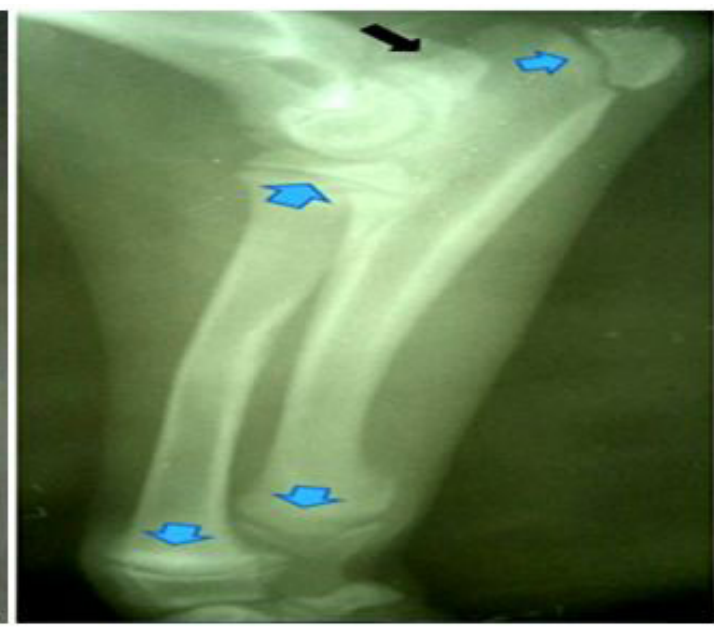

Figure 8: (12 weeks)

Partial ossification was observed 4 weeks before the final ossification of each of the growth plate of some growth plates like early signs (Partial ossification) of growth plate closure. That of the ulna bone was radiographically noticed at 20 weeks in 13 dogs (6 males and 7 females) which was also noticed on other growth plates but the complete ossification of the growth plates of all the dogs were observed to be 24 weeks (Figure 13) for proximal ulna, 28 weeks (Figure 14) for the proximal radius, 32 weeks (Figure 15) for the distal ulna and finally the distal radius that close at 36 weeks in 13 dogs ( 6 males, 7 females), 3 dogs ( 2 males, 3 females) fused at 40 weeks (Table 1,2 and 3). Considering the early signs of closure (partial union), the closure time for proximal and distal radius can be said to have a range of 24-28 and 32-40 weeks respectively while the proximal and distal ulna were 20-24 and 28-32 weeks respectively (Table 1).

\begin{tabular}{|c|c|c|}
\hline Growth plate & $\begin{array}{c}\text { Age at appearance } \\
\text { (Weeks) }\end{array}$ & $\begin{array}{c}\text { Age at closure } \\
\text { (Weeks) }\end{array}$ \\
\hline Distal radius & $2-3$ & $32-40$ \\
\hline Proximal radius & $4-5$ & $24-28$ \\
\hline Distal ulna & $5-6$ & $28-32$ \\
\hline Proximal ulna & $7-8$ & $20-24$ \\
\hline
\end{tabular}

Table 1: Range of appearance and closure times of the Growth Plates of the radius and ulna bones

The measurement of the thickness of the growth plate of the male dogs were documented at 4 weeks interval. At week 1, no growth plate was found. At week 4 , the first thickness was measured in the distal radius as $0.91 \mathrm{~mm}$. At week 8 , all the growth plate of 
proximal and distal radius and ulna bones were present with the distal ulna having the largest thickness of $1.40 \mathrm{~mm}$ and proximal radius had the least thickness of $0.56 \mathrm{~mm}$ (Table 2 ).

\begin{tabular}{|c|c|c|c|c|}
\hline Age/weeks & Proximal radius/ cm & Distal Radius/ cm & Proximal Ulna / cm & Distal Ulna/ cm \\
\hline 1 & ND & ND & ND & ND \\
\hline 4 & ND & 0.91 & ND & ND \\
\hline 8 & 0.56 & 0.68 & 0.96 & 1.40 \\
\hline 12 & 0.77 & 0.76 & 0.72 & 1.38 \\
\hline 16 & 0.49 & 0.47 & 0.34 & 0.29 \\
\hline 20 & 0.35 & 0.46 & PU & 0.21 \\
\hline 24 & 0.32 & 0.46 & Fused & PU \\
\hline 28 & PU & 0.32 & Fused & Fused \\
\hline 32 & Fused & PU & Fused & Fused \\
\hline 36 & Fused & (6 fused 2 not) & Fused & Fused \\
\hline 40 & Fused & Fused & Fused & Fused \\
\hline 44 & Fused & Fused & Fused & Fused \\
\hline 48 & Fused & Fused & Fused & Fused \\
\hline
\end{tabular}

NOTE: ND: Not developed; PU: Partial union

Table 2: Mean thickness of growth plate of radius and ulna bones in $\mathrm{mm}$ and closure time in males

\begin{tabular}{|c|c|c|c|c|}
\hline Age/weeks & Proximal Radius/ cm & Distal Radius / cm & Proximal Ulna / cm & Distal ulna / cm \\
\hline 1 & ND & ND & ND & ND \\
\hline 4 & ND & 0.94 & ND & ND \\
\hline 8 & 0.54 & 0.80 & 1.36 & 1.38 \\
\hline 12 & 0.67 & 0.71 & 0.96 & 1.30 \\
\hline 16 & 0.37 & 0.55 & 0.25 & 0.31 \\
\hline 20 & 0.32 & 0.48 & PU & 0.22 \\
\hline 24 & 0.31 & 0.41 & Fused & PU \\
\hline 28 & 0.26 & 0.22 & Fused & Fused \\
\hline 32 & PU & 0.22 & Fused & Fused \\
\hline 36 & Fused & PU (7 fused 1 not $)$ & Fused & Fused \\
\hline 40 & Fused & Fused & Fused & Fused \\
\hline 44 & Fused & Fused & Fused & Fused \\
\hline 48 & Fused & Fused & Fused & Fused \\
\hline
\end{tabular}

NOTE: ND: Not developed; PU: Partial union

Table 3: Mean thickness of growth plate of radius and ulna bones and closure time for females

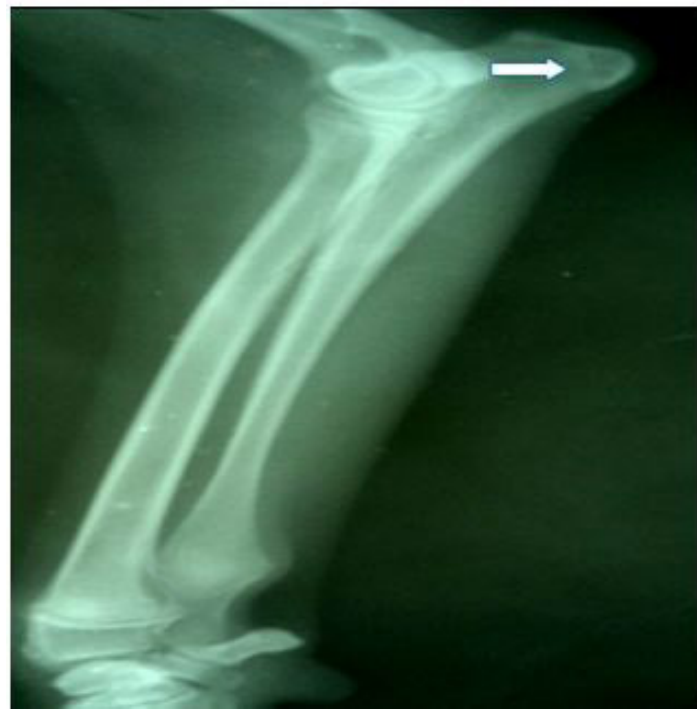

Figure 9: (24 weeks)

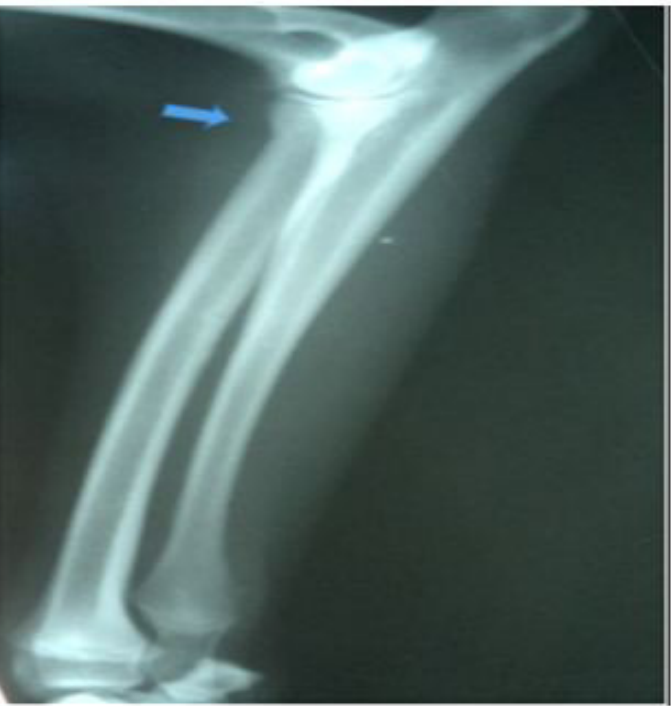

Figure 10: (28 weeks) 


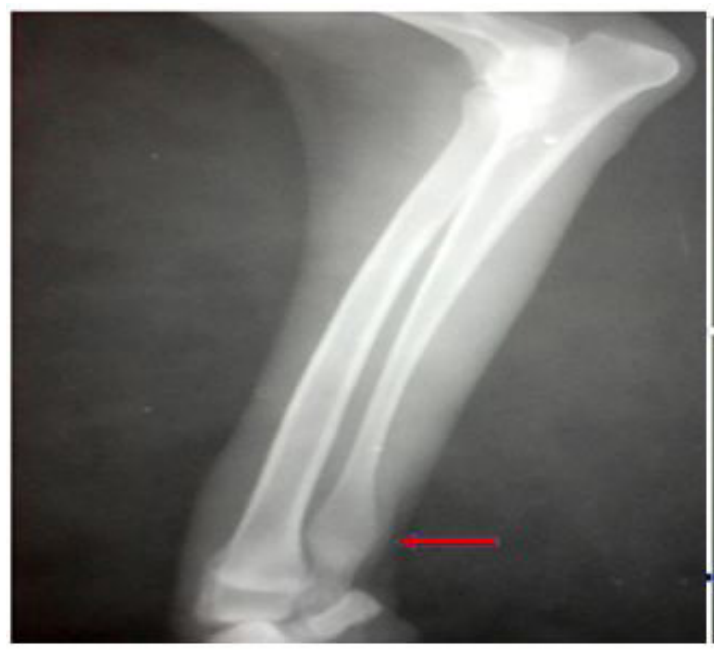

Figure 11: (32 weeks)

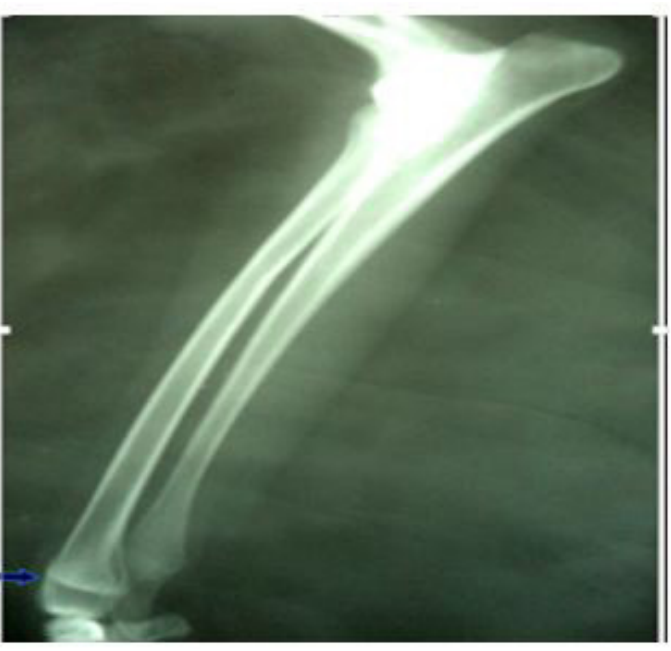

Figure 12: (36 weeks)

In the female dogs, at the week 1 of radiography, no growth plate was formed as well. At week 4, the first thickness was measured in the distal radius as $0.94 \mathrm{~mm}$. At week 8 , all the growth plate of proximal and distal radius and ulna bones were present with the distal ulna having the largest thickness of $1.38 \mathrm{~mm}$ and proximal radius having the least thickness of 5.4mm.The largest thickness of the growth plate in both males and females were observed at their time of appearance and kept reducing as the animal grew older until they finally fused (Table 3).

\section{Discussion}

From this study, a radiolucent structure, extending longitudinally between the epiphysis and metaphysis of these bones at different times is known as the growth plate which appeared after the appearance of epiphysis. This is in line with the work conducted by [22] who reported a radiolucent space between the epiphysis and metaphysis to be the growth. The appearance of the growth plate of the distal radius was at 2-3 weeks, proximal radius at 5 weeks, distal ulna at 6 weeks and proximal ulna at 8 weeks. This is similar to the work documented by [11] who reported that the distal radius appeared at 2 weeks and the proximal radius at 4 weeks, distal ulna at 6 weeks and proximal ulna at 8 weeks. The difference between their work and ours is the time of appearance of the proximal radius which appeared at 5 weeks in ours rather than the 4 weeks of theirs, this could probably be due to breed variation. This work was contrary to the work conducted by [9], who reported the appearance of proximal and distal growth plate of the radius to be prenatal and that of the proximal and distal ulna to appear between 3-4 weeks for giant breeds of dogs. These differences might be due to genetic, nutritional or environmental factors.

Our findings revealed that the thickness of the growth plate was larger at the time of appearance and kept decreasing as the animal grew older until partial union was observed which led to a complete closure of the growth plate. This followed a similar pattern with the work conducted by [6] and [23] and who reported a complete closure of the epiphyseal plates to occur by gradual displacement of the radio lucent area of the growth plate by radiopaque area (Partial union) until the bone becomes a single bone.

In the present study, the first growth plate to close in the radius and ulna bone was the proximal ulna which closed at 24 weeks, followed by the proximal radius at 28 weeks while the distal ulna fused at the age of 32 weeks and finally the distal radius at 36 weeks for most of the dogs, although a little delay was observed in the closure time of the distal radius in 3 dogs ( 2 males, 1 female) which finally closed at 40 weeks. The difference in the closure times of the 3 dogs could probably be due to genetic variation within the same breed due to the nature of their breeding (mixed breeding). The age of the growth plate closure of the radius and ulna bones in this study differs from the study conducted by [9] who reported the average time of closure of the growth plates of the proximal ulna to be 46 weeks, and proximal radius to be 49 weeks. The average closure time of the distal growth plate of the ulna and radius was 60 weeks in giant breeds of dogs. This could probably be due to genetic variation and nutrition. The range of appearance and closure of the growth plate among all the dogs for proximal and distal radius were 2-3 and 4-5 weeks respectively while for the proximal and distal ulna were 5-6 and 7-8 weeks respectively. A complete closure of all the growth plates of the radius and ulna bone were achieved at 40 weeks which is contrary to the 60 weeks reported by [9] for giant breeds of dogs [9]. This result is supported by the report of [24] and [25] who reported that among domestic breeds of dogs, small breeds attain maturity earlier within seven months to one year while large and giant-breed dogs might not be fully grown until they are eighteen months.

Our findings showed no statistically significant difference in the time of growth plate closure between male and female dogs although most of the females closed slightly earlier than the males (Table 3 and 4) and similar findings were reported by [26] and [27] and who documented that sex had no influence on the time of closure of the growth plate whereas [28] Smith and documented variations due to sex. This could probably be due to the breed of dogs used and their management system. 


\section{Conclusion}

The range of age at appearance of growth plate for proximal and distal radius were 2-3 and 4-5 weeks respectively while the proximal and distal ulna were 5-6 and 7-8 weeks respectively. The closure time for proximal and distal radius had a range of 24-28 and 32-40 weeks while the proximal and distal ulna were 20-24 and 28-32 weeks respectively. The thickness of the growth plate was wider at the time of appearance of the growth plate and kept reducing till they finally fused. Therefore, the appearance of all the growth plates of radius and ulna bones in Nigerian indigenous dogs were post-natal and fused at 40 weeks.

\section{Acknowledgement}

The authors appreciate the contributions of Professor JB Adeyanju, Dr AA Abubakar and Dr SherifatBalogun, Dr SM Atabo for their contributions and support towards the success of this work.

\section{References}

1. Netter FH (1987) Musculoskeletal system: anatomy, physiology and metabolic disorders. Summit, New Jersy: Ciba-Geigy corporation 8: 130.

2. Aslanbey D (2002) Veterinary Orthopedics and Traumatologie, Malatya, Turkey 3-7.

3. Douglas SW, Herrtage ME, Williamson HD (1987) Principles of veterinary radiography. Ballikre Tindall, London. Philadelphia; part 2: 339.

4. Bryan HD, Gerald JT (2005) Principles of Anatomy and Physiology. New York, Wiley ISBN 0471-6893, 110-5.

5. Kilborn SH, Trudel G, Uhthaff H (2002) Review of growth plate closure compared with age at sexual maturity and lifespan in laboratory animals. Contemp Top Lab Anim Sci 41: 21-6.

6. Todhunter RJ, Zachos TA, Gilbert RO, Erb HN, Williams AJ, et al. (1997) Onset of epiphyseal mineralization and growth plate closure in radiographically normal and dysplastic Labrador retrievers. J Am Vet Med Assoc 210: 1458-62.

7. Fukuda S, Matsuoka O (1980) Comparative studies on maturation process of secondary ossification centers of long bones in the mouse, rat, dog and monkey. Jikken Dobutsu 29: 317-26.

8. Conemius MG, Smith GK, Brighton CT, Marion MJ, Gregor TP (1994) Analysis of physeal growth in dogs, using biplanar radiography. Am J Vet Res 55: $22-7$.

9. Von Pfeil DJ, DeCamp CE (2009) The Epiphyseal Plate: Physiology, Anatomy, and Trauma. Compend Contin Educ Vet 31: E1-11.

10. Charjan RY, Sathapathy S, Banubakode SB, Joshi SK (2014) The developing radius, ulna, carpals, metacarpals and phalanges of right forelimb in different breeds of dog (Canisfamiliaris). Ind J Vet Ana 26: 76-8.

11. Myo NZ, Po SP, Soe HY, Myint HH, Khaing KT (2016) Comparison on Development of Ossification Centres of Radius and Ulna in Male and Female Dogs by Radiographically. Int J Nov Res Life Sci 3: 18-29.

12. Vazquez-Auton JM, Villa Lopez MI, Moreno F, Gil F, Latorre R (1993) Chronology of the postnatal ossification of sholder and elbow joints in the Siamese cat (Feliscatus L.) Anat Histol Embryol 22: 26-38.

13. Oishi, A, Hamada S, Sakamoto H, Kamiya S, Yanagida K (1996) Radiographic evaluation of bone maturation in Japanese black Cattle. J Vet Med Sci 58: 529-35. 14. Hofmann MI, Schradin C, Geissmann T (2007) Radiographic evaluation of neonatal skeletal development in Callimicogoeldii reveals closer similarity to Calithrixjacchus than to Saguinus Oedipus. Am J Primatol 69: 420-33.

15. Genccelep M, Aslan L, Bakır B, Atasoy N, Tas A (2002) Determination of the Closure Time of Growth Plates of Radius-ulna in Morkaraman Lambs by Radiography. YYU Vet Fak Derg 13: 1-7.

16. Genccelep M, Karasu A, Alpdogan O (2012) The determination of radius-ulna closure time of growth plates in Monhair goat Kids by radiography. Small Rum Res 103: 182-6.

17. Brown MP, MacCallum FJ (1975) A system of grading ossification in limbs of foals to assist in radiologic interpretation. Am J Vet Res 36: 655-61.

18. Fretz PB, Cymbaluk NF, Pharr JW (1984) Quantitative analysis of long bone growth in horses. Am J Res 45: 1602-9.

19. Fossum TW (2002) Fundamentals of orthopaedic surgery and f racture management. 933.

20. Singh AP, Singh J (2001) Basic principles of radiography and radiographic positioning. CBS Publishers and Distributors 88-105.

21. Douglas SW, Herrtage ME, Williamson HD (1987) Principles of veterinary radiography. Ballikre Tindall, London. Philadelphia; part 2: 339.

22. Brighton CT (1978) Structure and function of the growth plate. Clin Orthop Relat Res 136: 22-32.

23. Youssef GB, Bakry HH, El-Shwarrby RM, El-Aliem NMA, El-Shewy EA (2016) Medicolegal importance of radiographic images of humerus in determination of age in sheep and goat. Sch J App Med Sci 4: 806-11.

24. Van Ballenberghe V, Mech LD (1975) Weights, growth, and survival of timber wolf pups in Minnesota. J Mammal 56: 44-63.

25. Cupps PT (1991) Reproduction in domestic animals. San Diego: Academic Press.

26. Sumner-Smith G (1970) Bone plating for radial fractures in small dogs. Modern Vet Pract 57: 30.

27. Salmeri, KR, Bloomberg MS, Scruggs SL, Shille V (1991) Gonadectomy in immature dogs: effects on skeletal, physical, and behavioral development. J Am Vet Med Assoc 198: 1193-203.

28. Smith RN, Allcock J (1960) Epiphysial fusion in the greyhound. Veterinary Record 72: 75-9. 